\title{
SELLING COOL: \\ A VISUAL ANALYSIS OF APPLE'S BRAND IDENTITY
}

\author{
by \\ Heather McVetty \\ B.A., Carleton University 2017 \\ Major Research Paper \\ Presented to Ryerson University \\ In partial fulfillment of the requirements for the degree of \\ Master of Professional Communication \\ In the program of \\ Faculty of Communication and Design
}

Toronto, Ontario, Canada, 2020

(C) Heather McVetty, 2020 


\section{Author's Declaration for Electronic Submission of a Major Research Paper}

I hereby declare that I am the sole author of this Major Research Paper. This is a true copy of the MRP, including any required final revisions, as accepted by my examiners.

I authorize Ryerson University to lend this MRP to other institutions or individuals for the purpose of scholarly research.

I further authorize Ryerson University to reproduce this MRP by photocopying or by other means, in total or in part, at the request of other institutions or individuals for the purpose of scholarly research.

I understand that my MRP may be made electronically available to the public. 


\title{
SELLING COOL: \\ A VISIAL ANALYSIS OF APPLE'S BRAND IDENTITY
}

\author{
Heather McVetty \\ Master of Professional Communication \\ Ryerson University, 2020
}

\begin{abstract}
Apple Inc. has positioned itself in the minds of consumers as cool and innovative by carefully creating and curating a brand identity by highlighting experience, disruption, and contrast. This research explores how Apple has harnessed its brand to convey to consumers that its products are cool and innovative. Based on literature looking at the impacts of product design, branding, and conveying innovation, this visual analysis explores how Apple uses unique design to convey an image of product innovation, and how it conveys product innovation through video advertisements. It looks specifically at some of Apple's iconic campaigns; 1984, Are You Gonna be My Girl, and This is Your iPhone. Taken as a group, the analysis of these campaigns suggests how Apple conveys a cohesive brand identity and presumptive product innovation and how it denotes innovation with the branding aesthetics in its advertisements. By focusing on its brand image, radical design, and user experience - rather than the technical aspects of its products Apple has been able to convey innovation and cool to consumers.
\end{abstract}




\section{Acknowledgments}

I would like to thank Dr. Carolyn Kane for her support, guidance, and academic expertise, without her this project would not have been possible. Similarly, I would like to thank Dr. Joanne Di Nova for her insights and review of this project as my second reader.

Additionally I would like to Acknowledge that Ryerson University is situated on the traditional territory of the Wendat, the Anishnaabeg, Haudenosaunee, Métis, and the Mississaugas of the Credit First Nation. 


\section{Dedication}

I dedicate this paper to my friends and family. I am so grateful that I have been able to build such an amazing and supportive group of people around me in Winnipeg, Ottawa, and Toronto.

Thank you. 


\section{Table of Contents}

\section{A. Front Matter}

Author's Declaration....................................... page ii

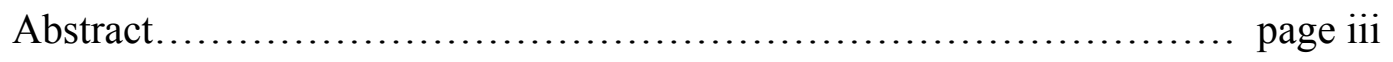

Acknowledgements......................................... page iv

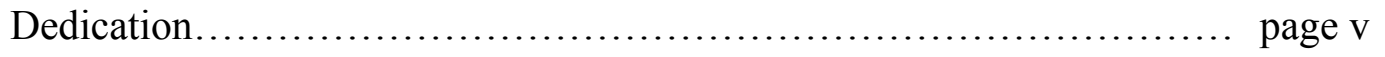

Table of Contents......................................... page vi

List of Appendices........................................... page viii

\section{B. Main Body}

1. Introduction.............................................. page 01

2. Literature Review...................................... page 02

2.1 Product Design $\quad$ page 03

2.2 Branding page 06

2.3 Innovation $\quad$ page 09

3. Research Questions ........................................ page 11

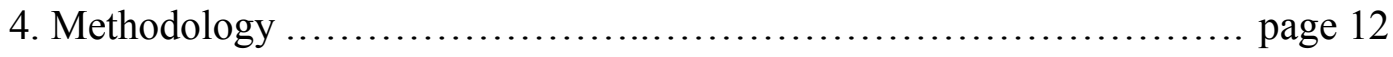

5. Findings and Discussion................................. page 14

5.1 Visual Analysis - Discussion of Results page 15

5.2 Visual Analysis - Interpretation of Findings page 24

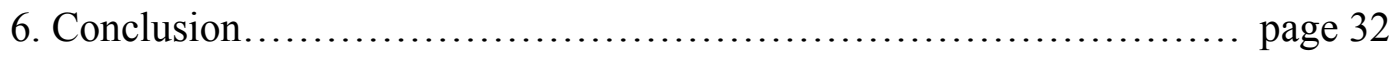

6.1 Significance of Findings $\quad$ page 32

6.2 Limitations and Implications $\quad$ page 34 
Reference List......

\section{Back Matter}

Appendix A........................................................ page 39

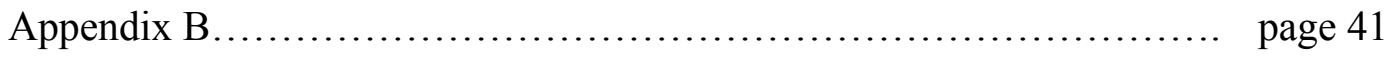

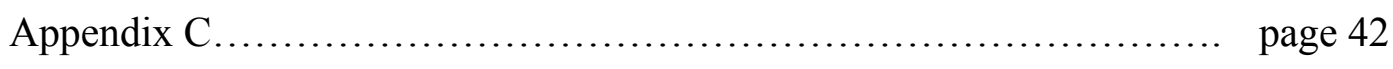




\section{List of Appendices}

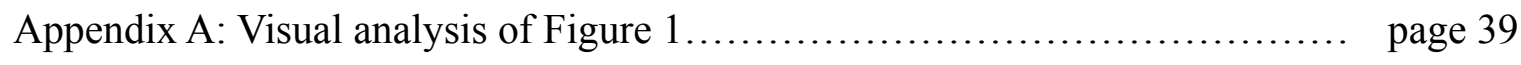

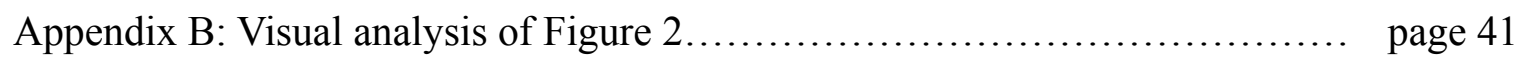

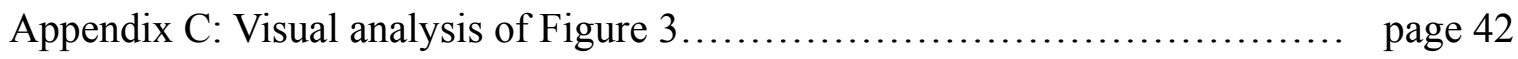




\section{Introduction}

Apple products have developed a reputation in the small electronics market for being original and influential. Building on the popularity of its Macintosh personal computers, Apple has positioned itself as an innovative and technologically-advanced brand, with many consumers and industry watchers considering it as the benchmark for effective product design and electronic interactions. Apple has harnessed its radical designs and cohesive brand identity to position itself as a cool, innovative brand in consumers' eyes (Firmin et al., 2013).

Is it important to be perceived as cool and innovative? While individuals often seek to build such a reputation, how does it help a multinational company? The reason is that it can be a clever business strategy; allowing them to get more return on their advertising investment. Product advertising that focuses on product features needs to be updated with every iteration of the product. For large multinational brands with diverse product lines, this would be impossibly expensive. But positioning the brand itself as a symbol of cool and innovation effectively allows Apple to advertise all of its products with each advertisement. Additionally, this helps persuade consumers to take note of its new products and to purchase new Apple technology - whether or not their old technology still works - when they consider a competing brand. Cool, as defined by Pountain and Robins (2000) is the idea of status driven by consumption, highlighting indulgence and sophistication of the owner.

This paper uses Rose's (2016) visual analysis framework to explore how Apple uses experience, disruption, and contrast to position its products. This framework can be an effective way to understand the ways in which a firm uses its advertising to convey an image. 
A significant body of research in marketing and product innovation looks at the myriad ways in which consumers are swayed by product design and product newness, but few explore how Apple uses its branding and aesthetic to persuade consumers that its products are superior to competitors. Numerous branding and product innovation studies address how consumers perceive products on the market with radical product designs, and the benefits of having a cohesive brand identity (Veryzer \& Hutchinson, 1988). This research goes beyond the impacts of product design, branding, and conveying innovation, to explore how Apple harnesses its brand to convey to consumers that its products are cool and innovative.

Findings are based on a comprehensive visual analysis of Apple's landmark 1984 commercial for the Macintosh computer, its iconic Are You Gonna be My Girl campaign, and its This is Your iPhone video advertisement. Taken as a group, the visual analysis explores how Apple conveys a cohesive brand identity and presumptive product innovation and how the company denotes that innovation with the branding aesthetics in its advertisements. By using a combination of experience, disruption, and contrast, Apple has been able to leverage its brand identity and position its products in the psyche of the public as innovative and cool (Hedman \& Gimpel, 2010).

\section{Literature Review}

A significant body of technological innovation research explores the value of product design, radical design integration, brand context, and innovative items as status markers (Blosh, 1995; Durgee et al., 2016; Cecilia Russo \& Ferrara, 2017; Talke, 2009). Reviewing this 
literature establishes an overview of the current thought on product design, branding, and innovation, and establishes the context for the visual analysis that follows.

\section{Product Design}

Apple's unique product design sets it apart from other brands that serve the same functions; the only meaningful difference is design (Durgee et al., 2016; Talke et al., 2009). Using design as a competitive tool means that the company emphasizes its importance as a feature of Apple products (Talke et al., 2009). Design is considered to be an integral characteristic of a product, critical to marketplace success and consumer approval (Bloch, 1995; Liu et al., 2017). Good product design attracts customers, adds value by making users' interactions with the product more positive, and helps the consumer believe that the product is of higher value (Blosh, 1995; Xue, 2019).

Following the postmodernism of the 1980's, aesthetics begun to play an increasingly important role in the social acceptance of technology (Eggink \& Snippert, 2017). In this context, postmodernism is defined as a situation in which "the loss of a single truth is not rooted in relativism or in the individual's choice of moral codes but is based on the reality that people with different ethnic, cultural, social, class, and economic frames of reference have very different realities" (Holtzhausen, 2000, p. 96). Postmodernism plays a key role in a global marketplace for companies that need to sell products across ethnic, cultural, and social lines. Thus, Blosh (1995) suggested that the market was seeing a design renaissance, mirroring that of the 1930s, in which good design gave products a competitive edge. Dong (2015) refers to this shift as the 'design turn' in which the value of design gained the social acceptance that we see today. For 
Eggink and Snippert (2017), postmodernism also re-introduced the elements of emotion and cultural reference into the design of products entering the marketplace.

Durgee et al. (2016) suggest that it was postmodernism that drew attention to design, and highlights its impact on consumer behaviour, emphasizing the fine line between innovative and deterrent design. They found that consumers tend to reject designs as 'too radical' when they do not understand the new meaning. This idea is supported by Cecilia Russo and Ferrara (2017) who believe that drawing on common behaviours, shapes, and rituals can accelerate consumers' acceptance of new technologies. As a result of this postmodernism transition, Veryzer and Hutchinson (1988) credit aesthetics as influencing consumer acceptance and giving brands a competitive advantage even in saturated markets.

Blosh (1995) suggests that a product's appearance is a major indicator of how well it will do on the marketplace. In short, good design draws attention and suggests a better user experience than other options on the market and consumers are more likely to purchase a product that looks cool based on aesthetic value (Blosh, 1995; Xue, 2019). This is what Liu et al. (2020) consider to be 'design novelty,' or the degree to which the design of a new product deviates from others on the market. For Talke et al. (2009), companies that monetize design novelty, like Apple, maintain a customer base that seeks ways to show brand affiliation and self expression. Simply put, design novelty attracts public attention, and Liu et al. (2017) found that attention is a function of the degree to which product design deviates from others on the market; the more it deviates from the norm, the more attention it will receive, noting that attention does not necessarily equate to acceptance. Releasing products with unique designs helps Apple to 
capitalize on its own advertising with little fear that consumers will confuse its advertising for that of a competitor (Liu et al., 2017).

But the impact can be deeper than simple curiosity. Blosh (1995) finds that the ideal design draws positive associations, emotions, and responses from consumers. It does more than simply foster attention; a well-designed product will also increase consumers' perceptions of quality, make them more likely to purchase the product, and more likely to recommend it (Xue, 2019). In fact, Hedman and Gimpel (2010) identified the unique design of the original iPhone in 2007 as responsible for much of the product's hype prior to its worldwide release.

But, while design novelty can indicate competitive advantage, consumers need to see the product to understand its design innovations. For this reason, how a company reveals the product also plays an important role in public perception. Durgee et al. (2016) reinforce this idea, concluding that the best way to market radical product designs is to include the designer philosophy with the product. Apple does this pairing of radical design and designer philosophy quite well, hosting product events to unveil new products and have an Apple expert explain the product design (Durgee et al., 2016). By carefully curating consumer experience, Apple differentiates its products from others on the market while simultaneously communicating and even creating value for them (Gilal et al., 2018).

Apple set the original iPhone apart aesthetically from the other phones at the time and its unique qualities elicited a positive emotional association even before it's 2007 American release and 2008 worldwide release (Hedman \& Gimpel, 2010; West \& Mace 2010). Apple carefully 
crafted these releases to launch the most successful and curated launch possible (West \& Mace, 2010).

Thus, good design helps a company to draw attention to a product, ensure that its advertising is uniquely its own, and create excitement prior to a release (Blosh, 1995; Liu et al., 2017; West \& Mace 2010). Those seeking to gain attention in the marketplace must be cognizant of consumers' motivations and if their product design will attract positive attention and increase sales, or whether it will be confused or disliked and thus deter new potential customers.

\section{Branding}

As the design of individual products becomes increasingly important, the overall brand context becomes more important than the traditional focus on single products (Cecilia Russo \& Ferrara, 2017). The idea of designing items across a brand with an aligned look allows for a cohesive family of products, creating a feeling of interconnectedness in the product lineup (Blosh, 1995). Cecilia Russo and Ferrara (2017) find that this shift toward a cohesive brand identity is a trademark of this modern era, in which designers focus on brand context more than on single items from a brand.

According to Wilner and Huff (2017), product design is directly correlated to the overall success of brands. By maintaining a cohesive brand identity across all products, those that have adapted radical designs can promote an entire brand with advertisements for individual products (Durgee et al., 2016). Therefore, adopting a radical design and cohesive brand identity may increase consumer demand for all products associated with the brand itself (Liu et al., 2017). 
Blosh (1995) uses Apple as an example of the shift to 'brand identity through design,' describing how the design of Apple products has driven the brand, especially after the first Apple Macintosh computer was released in 1984. For Blosh (1995), the computer's 'friendliness' and its unique design gave the brand a distinct look and feel in the crowded electronics market. In fact, the friendliness of Apple's products has attracted much attention from scholars and consumers alike. This personification is often cited as being a symptom of the colours used, friendly brand name, and anthropomorphic design (Talke et al., 2009; Keller, 2013; Bloch, 1995).

This idea is supported by Liu et al. (2017), who conclude that a brand-consistent design increases the promotional value of a company's advertising and can increase demand for all of its products. For companies that maintain recognizable brand consistency, consumers can associate products with their specific brand, creating higher demand for all the company's products (Liu et al., 2017). According to Eggink and Snippert (2017) this level of brand consistency makes it easier for consumers who are not tech-savvy (e.g., those who may typically reject a more innovative product design) to integrate and adopt the brand..

As Apple meticulously upholds a brand shrouded in mystery, it is able to play up the novelty of the technology (epistemic value), the passion it ignites (emotional value), and the social image attached to the products (social value) (Hedman \& Gimpel, 2010). This sense of mystery, in turn, drives public curiosity about the product itself, creating excitement on blogs and social media platforms external to Apple. The company has been known to encourage local owners of its products to congregate and form Apple user groups (Keller, 2013). 
For Spaulding (2010), it is not a new concept for a brand to leverage an online community to foster brand loyalty and unity across digital platforms. Apple fans draw on the epistemic and social value of the products and the technology in these online communities, and it becomes a discussion topic for those who seek to keep up with new technologies, and - by exposure - may become loyal to the Apple brand (Hedman \& Gimpel, 2010). For Hedman and Gimpel (2010) this 'fandom' in turn raises the social value of the product, granting an owner of the product a higher social status in return. Apple also calculates the releases of its products, launching the iPhone after the success of its iTunes music service and its iPod music player (West \& Mace, 2010).

But when does innovative design become too radical for the mass market? According to Durgee et al., (2016) Apple used cohesive branding and design throughout its product line and reinforced its brand through a cohesive look and feel of all of its products. Thus, Apple has developed and consistently reinforced a corporate brand and feel recognizable to consumers (Blosh, 1995). Apple is unique because of its desire to lead the market with innovative design, not simply follow what the market wants (Durgee et al., 2016). While a leadership strategy is more difficult than a strategy to follow the market, branded storefronts help to maintain a consistent brand image for consumers, who are then more willing to accept innovative design.

Gehani (2016) posits that Apple created this aura of innovation by restructuring the design process of its products, starting with the user experience, and having its engineers work backwards from that point. This user-centric design model has helped attract consumers to Apple 
products, supported by the functional innovation and pleasing design of its physical products and cohesive brand image.

Blosh (1995) notes that consumers view products and their brands based on how they are displayed in a retail setting. Apple has come to be known for its tailored branded shopping experience, helping consumers make positive brand associations with its products and by appealing to consumers' emotions (Xue, 2019). With the unveiling of its brick and mortar Apple stores (iStore) in 2001, Apple could interact directly with consumers and build and share its brand mystique (Gehani, 2016). The retail stores allowed Apple to display its products and brand directly to consumers in a mediated and controlled setting.

\section{Innovation}

Companies like Apple are driven by innovation as a means of market differentiation. Although the computer itself had similar functionality to Windows-based computers, the iMac had a new appealing and innovative design and user interface (Liu et al., 2017; Gehani, 2016).

Durgee et al. (2016) cite this as an example of how radical design can sway consumers' perceptions of an item. According to Durgee et al. (2016), while the iMac had similar features to other products on the market, its new design set it apart and changed consumers' ideas of what a computing device should look like. Prior to the release of the iMac, personal computers were considered mundane electronic device designed to serve a technological function. The iMac changed this, becoming the first personal computer simultaneously designed to function as room decor (Talke et al., 2009). 
This reinforces Dong's (2015) hypothesis that innovation is more about a unique user experience than the technological innovation behind the screen. This success can be seen with the unveiling of the original iPhone in 2007. This new iPhone boasted many features standard to many other phones on the market like email, a calendar, and voice connectivity (West \& Mace, 2010). The features on the iPhone that were unique to the phone were not necessarily new to the market either, with one of the main selling features of the phone being a music player functionality already available as Apples best-selling iPod (West \& Mace, 2010).

For Xue (2019), using product design in place of actual technological innovation is a way of keeping consumers interested in a product, and by extension, loyal to a brand. As companies release new technologies at an increasing rate, the potential for meaningful innovation is limited. Therefore, brands are forced to find other ways to maintain the purchasing cycle (Xue, 2019). Gehani (2016), however, points out the risk in simply promoting perceived innovation over actual innovation, as brand reputation will suffer if a product does not fulfil its promises.

In crowded markets, consumers have the choice of many products that serve the same essential functions, differentiated primarily by product design and perceived innovation (Talke et al., 2009). In these cases, design provides consumers with cues which influence the perception of a product, and willingness to buy and recommend it to others (Xue, 2019).

According to Talke et al. (2009) design innovation can increase a product's sales performance if consumers feel that ownership will raise their own social status. In other words, consumers want to purchase products that they see as innovative because being seen to own these products makes a statement about their own status (Talke et al., 2009; Liu et al., 2020). 
Liu et al. (2020) support this idea by concluding that product design has the ability to favourably sway consumers' perceptions of a product. For Liu et al. (2020), brands can promote innovative and unique design to those who are conscious of their outward appearance, and who seek status within their own communities. Popular and desirable items like the iPhone frame owners as trend setters and leaders in the technology community and stands to boost social standing of owners (Hedman \& Gimpel, 2010). This idea that radical design implies social status is not new, according to Durgee et al. (2016); the concept existed more than one hundred years ago as watches evolved from a way to tell time, to jewelry, to status symbols.

\section{Research Questions}

A visual analysis model will frame how Apple uses video advertising to convey its products as innovative. The literature on branding innovative technologies establishes that the public may be reluctant to desire consumer products that boast radical design, but Apple has successfully used design to create demand for its full range of products (Durgee et al., 2016). In the saturated personal technology space, other companies have achieved success with a small number of products, but none has matched Apple's success across the personal technology product line (West \& Mace, 2010).

To better understand the impact of visual images on product positioning, and its successful implementation as a business strategy, this paper explores Apple's video advertising over the decades. The research focuses on Apple specifically because of the success of its infamous 1984 Super Bowl commercial for the release of the Macintosh computer and its subsequent unique and culturally significant video advertisements (Graham, 2019). Apple campaigns tend to reflect, or 
even presage the cultural zeitgeist for their eras, and thus uniquely promote the brand as much as - or even more than - the specific products. The success and popularity of Apple video advertisements warrant detailed examination for the ways in which they consistently convey innovation through a series of short advertisements. This research examines two research questions:

1) How does Apple use unique design to convey an image of product innovation? How does Apple use its trademark minimalist style to convey its brand identity through video advertisements, and how does that help persuade the market that its products are more technologically advanced that competing products?

2) How does Apple convey product innovation through video advertisements? The literature review suggests that the word 'innovative' typically refers to user experience rather than technological developments, but Apple has been successful in conveying both. Thus, what tools does Apple use, including its minimalist brand identity, to position its products as innovative in the public psyche?

\section{Methodology}

In order to answer these research questions, I will be using a qualitative visual analysis approach. This analysis will be shaped by Gillian Rose's (2016) text Visual Methodologies. These methodologies respond to "the need to engage with visual culture" as the world continues to become increasingly mediated (Rose, 2016, xxi). During her search for a way to systematically study how an artifact looks, Rose has created a model for compositional interpretation that offers a framework to "look at images for 'what they are', rather than for, say, 
what they do or how they were or are used" in the public sphere (2016, p. 57). Specifically, Rose's (2016) compositional interpretation framework enables an analysis of visual signifiers and their significance within the ethos of Apple's branding. This framework is particularly salient for this study because I am focusing primarily on the efficacy of Apple's advertising for conveying design and innovation for the brand rather than their impact on specific product sales.

I will use this approach to deconstruct Apple's video advertisements for their use of colour, minimalism, and disruption, to help explain how the Apple frames its brand - not just its products - as innovative. The commercials I will explore are for three distinct products: the famous 1984 Macintosh computer commercial, the Are You Gonna be My Girl iPod commercial from 2003, and the 2007 This is Your iPhone commercial. These were all originally television commercials, but all three are available on YouTube. I chose these specific artifacts because of their cultural salience and because they are for distinct personal technologies. Each one was created to advertise the addition of a new product to the Apple lineup, stirring up intrigue and excitement for consumers.

The focus is on video advertising and not print. Much of Apple's advertising has become culturally significant, and its larger campaigns - like those for launches of the iPhone and iPod feature print components that mirror the style of the video. Because video contains the most information regarding sound and movement, this is the facet of Apple's advertisements I have chosen to focus on for this research.

This information is necessary for the analysis. Grounded in semiotics, Rose (2016) presents a framework for the observation of visual media. I will examine these advertisements using a visual analysis framework by coding the following variables: 
1. Content: As a record of what is depicted.

2. Colour: As a record of how colour is used to convey meaning.

3. Spatial organisation: As a record of how meaning is formed by the relation of objects.

4. Montage: As a record of how shots were filmed and edited together.

5. Sound: As a record of music, narration, development of soundscape.

6. Light: As a record of what elements are highlighted.

7. Expressive content: As a record of the 'mood' or 'atmosphere'.

By using this framework breakdown to study each artifact in a table, I will be able to view each element and more easily compare techniques used in its other successful advertisements. This systematic breakdown of different visual elements from Apple advertisements will allow for inferences and comparisons of findings between artifacts.

\section{Findings and Discussion}

Apple's has worked alongside its in-house advertising agency TBWA/Media Arts Lab to develop many advertisements which have placed Apple products in the public psyche, and subsequently their hands (Graham, 2019). This agency is a subsidiary of the Omnicom Group TBWA advertising agency that works exclusively in-house on advertising Apple products (Graham, 2019). 


\section{Discussion of results}

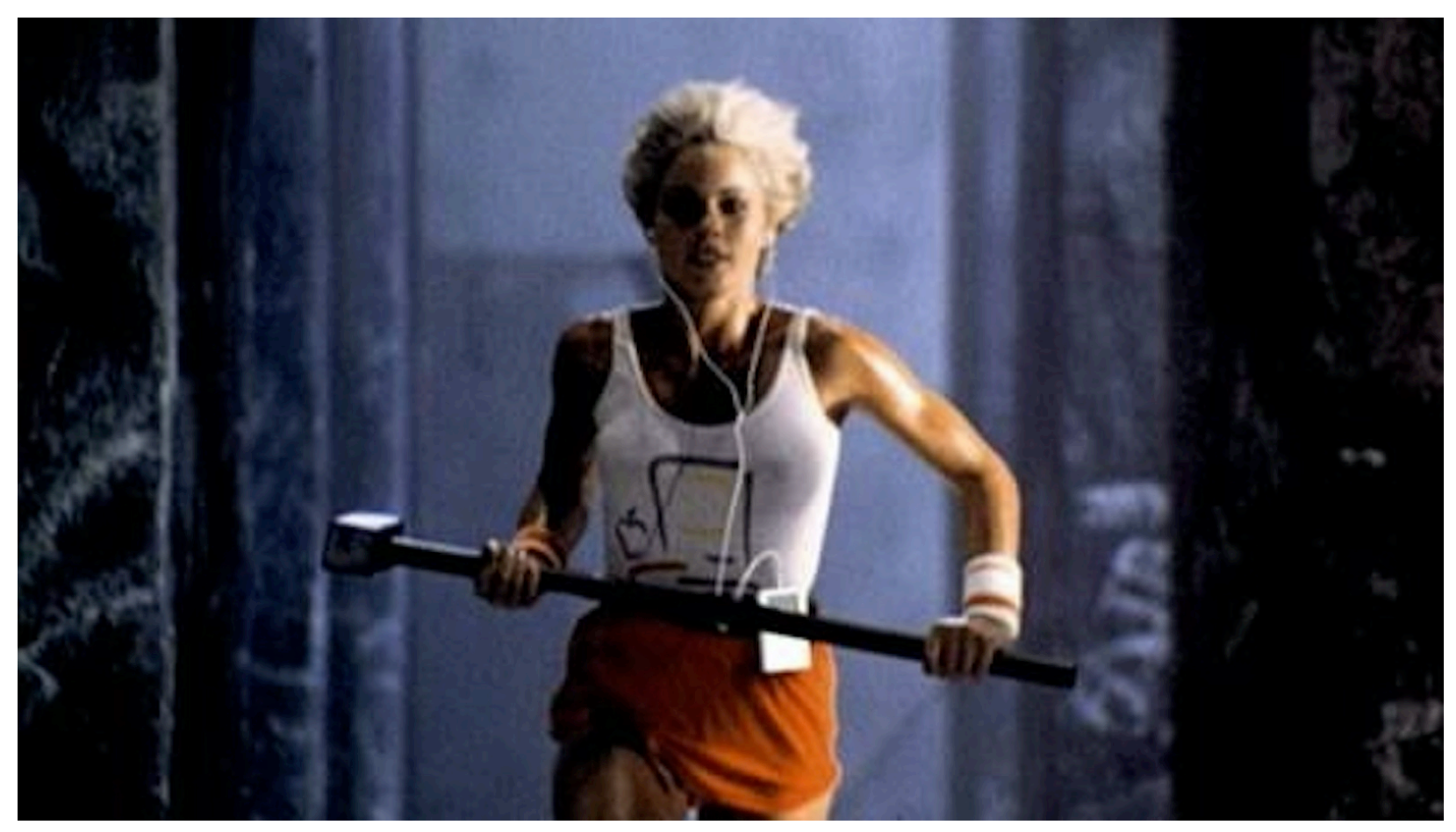

Figure 1

This 1 minute 1984 Super Bowl advertisement was the first advertisement for the Apple's first Macintosh computer. As the first advertisement for a new product, this commercial put Apple in the psyche of the public. As seen in Figure 1 this advertisement pulls on contrast and the high tension scenes showing how complacent everyone is, before the woman runs in and disrupts the scene, implying that the new Macintosh Computer will do the same. This advertisement does not actually feature the computer at all, but rather places Apple in the mind of the public, drawing up interest and providing an introduction to the Apple brand.

In terms of content this advertisement features an ominous cult-like world where a crowd of gender neutral people all gather to listen to the leader before a woman runs in, evading 
security with a hammer and throws it at the screen. Once the hammer pierces the screen all the people in the room appear stunned and frozen in shock.

By using colour, this advertisement highlights the differences between how thing are before the disruption, brought on presumably by the Macintosh Computer, and after. The advertisement is mostly grey, with the world and the wardrobes of those in it in cool toned shades. This is contrasted by the woman who runs in wearing red shorts and white tank top. At the beginning of the advertisement the scenes have a very low saturation, with the world featuring many muted blue-grey tones. It is not until the antagonist female is shown on screen in bright red shorts and a stark white tank top that there is highly saturated colour. After the hammer is thrown the world shown on screen becomes lighter as those followers become still and the saturation of the whole scene increases. Colour value in this advertisement provides additional context and contrast to the advertisement. Whereas the value of the beginning of the advertisement has a very low value, with the entire scene in hues of dark blue and grey, ends with a bright white scene after the hammer is thrown at the screen. The colour value of the antagonist is also contrasting from those 'followers' seen filing into the theatre. Whereas the 'followers' are wearing grey jumpsuits, the antagonist is wearing a high value white tank top and bright red shorts.

This advertisement uses spatial organization to add to the high tension feel. The perspective of this advertisement shifts as it progresses. The 'followers' are always shown from the ground looking up or above looking down. This is contrasted by the antagonist who is shown 
straight on at eye level until she is throwing the hammer and the camera is looking up at her as well. This advertisement features a use a combination of long, medium, and close-up shots.

In addition to the spatial organization, the way the advertisement is edited also adds to its tense nature. The scenes in this advertisement jump around quite quickly creating a jarring and high tension montage rhythm for the viewer. These clips begin wide and get closer and closer to the 'followers' as the camera follows them heading to a theatre to listen to a message on a large screen.

Sound is used to further the narrative for this advertisement. As the ad begins there is the sound of a mans voice muffled coming from what sounds like a loudspeaker however you are not able to hear where it is coming from until the 'followers' enter the theatre and you can see a man on the screen speaking to the people watching. This man is interrupted by the antagonist woman yelling as she throws the hammer followed by a cleaner voice reading the text that appears on screen "On January 24th, Apple Computer will introduce Macintosh. And you'll see why 1984 won't be like '1984'.”

This advertisement uses light to highlight the progression of the storyline. By introducing a dark scene, when the antagonist is shown in lighter clothes she immediately stands out from the others shown in the scene. Once the hammer is thrown into the screen and the text begins to play overlaid on the scene light is used to provide contrast for what Apple is insinuating as the dark world before the Macintosh computer, and the brighter future. 
The overall mood of the advertisement is that of optimism. Clearly depicting 'followers' blindly following each other around, this advertisement situates Apple as disruptive to the current status-quo.

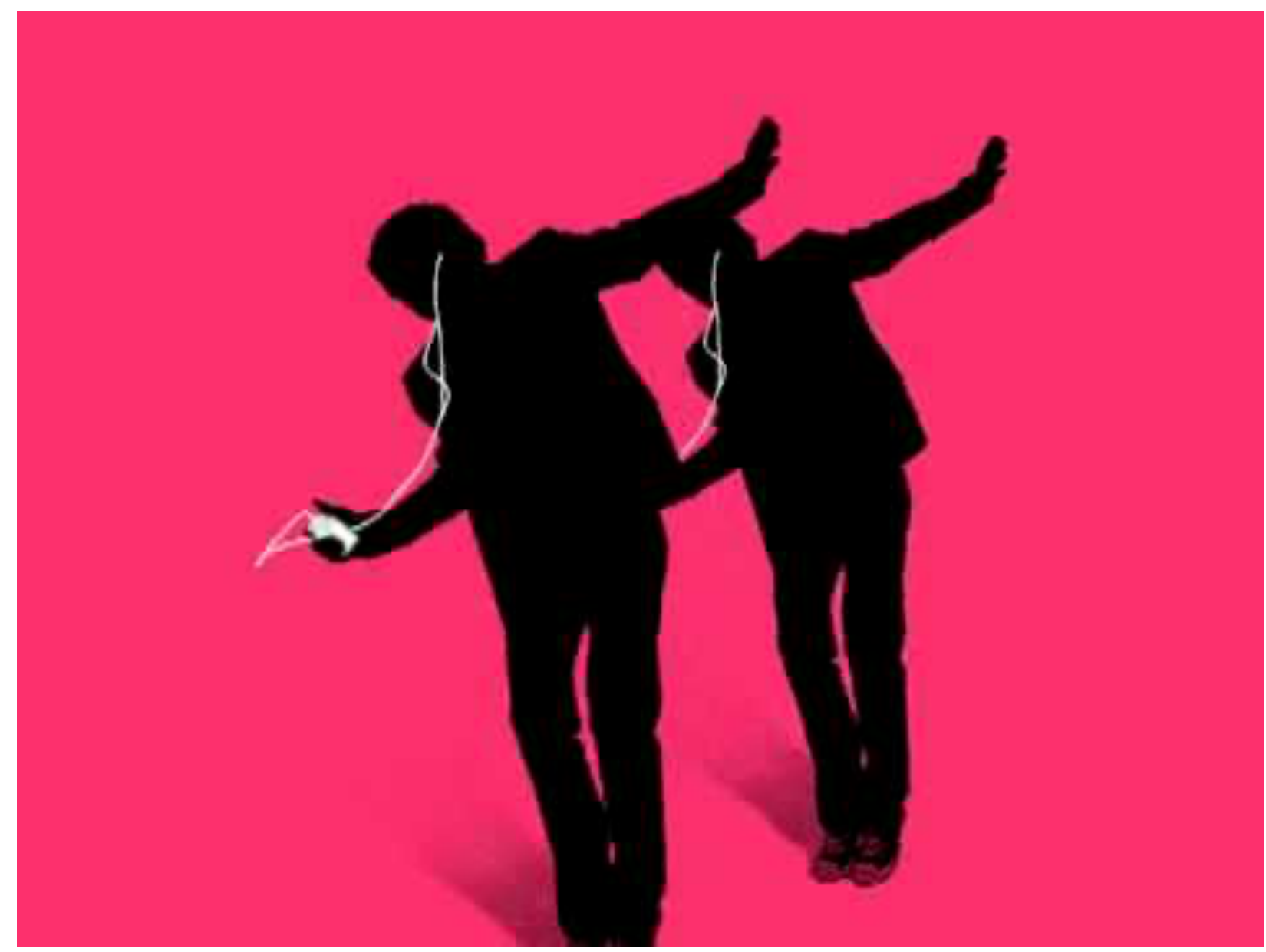

Figure 2

This 30 second advertisement released in 2003 was a part of the larger silhouette campaign. The silhouette campaign proved successful for Apple, with the series representing a shift for its products becoming a recognizable symbol. This advertisement was eye catching based on the high contrast and energy of the advertisement itself. This high contrast advertising campaign seen in figure 2 was simple enough to stand out from other more life like advertisements, but was also captivating with high intensity dancing, and catchy music. Although 
this advertisement is to sell the iPod, the iPod itself is not what the advertisement is centred around, rather the advertisement highlights the experience of having and using the device.

The content of this advertisement is upbeat, depicting silhouettes dancing energetically to music from their iPods with their white Apple headphones in. These minimalist advertisements from the silhouette campaign display nothing more than the silhouette of the subjects in black atop a colourful background holding an iPod and wearing Apple's recognizable white corded headphones. Although the silhouette itself is solid black, there is a great deal of movement coming from the dancers themselves, and through the movement of their clothing. This advertisement also highlights the movements of the silhouette's faces singing along to this music by using close ups of their faces.

Colour in this advertisement is used sparingly only used one at a time as the solid background however these colours are quite bright and eye-catching. This advertisement features a very minimalistic and streamline colour palate. The only colour used in the advertisement is the background of the advertisement itself, which alternates between lime green, yellow, hot-pink and purple. The only other items in the advertisement are the black silhouette of the dancer and the white iPod they are holding in their hand. The background colours used are highly saturated. Atop these highly saturated colourful backdrops the other items in the advertisement provide a stark contrast, as the black dancing figure is holding the white iPod and wearing white headphones so the product being advertised stands out even more. This advertisement plays on a stark contrast in the value of the colours used, as black has a very low value, the colourful backdrops and white iPhone have very high values. The contrasting values used in this 
advertisement make it very simple and eye-catching, but also highlight the iPod as an important feature of the advertisement with contrast.

The spatial organization of this advertisement is in line with the personal "dance like no one is watching" mentality featuring a combination of features a use a combination of long, medium, and close-up shots. The geometrical perspective also follows this model as the dancers in the advertisement are shown at eye level and through close ups of the dancers to show the movement of the clothing, and highlight the fact that the dancers are singing along to the song being played.

To continue the playful feel of the advertisement the clips in this advertisement create a montage switching almost seamlessly to the beat of the song playing in the ad. These clips are a combination of different shot distances combined in a way which highlights the silhouettes dancing and singing along to the song playing. The camera does not move during any of the clips.

In these visually minimalist advertising sound plays a critical role in engaging the audience and providing context to the movement featured. Are You Gonna Be My Girl by the rock group Jet is the only sound in the advertisement. Beginning with a heavy and catchy guitar solo, the ad quickly transitions to the lyrics of the song which are also engaging the audience with lyrics like "I say you look so fine; That I really wanna make you mine" and "now you don't need the money; When you look like that, do ya honey" playing on the idea of consumer culture, and the idea of purchasing the item, by just using the lyrics from the popular song itself. 
Overall the expressive content of this advertisement is high energy, happy and upbeat. The combination of the upbeat rock song, bright colours, and dancing and singing along that the silhouettes are doing make the advertisement fun to watch.

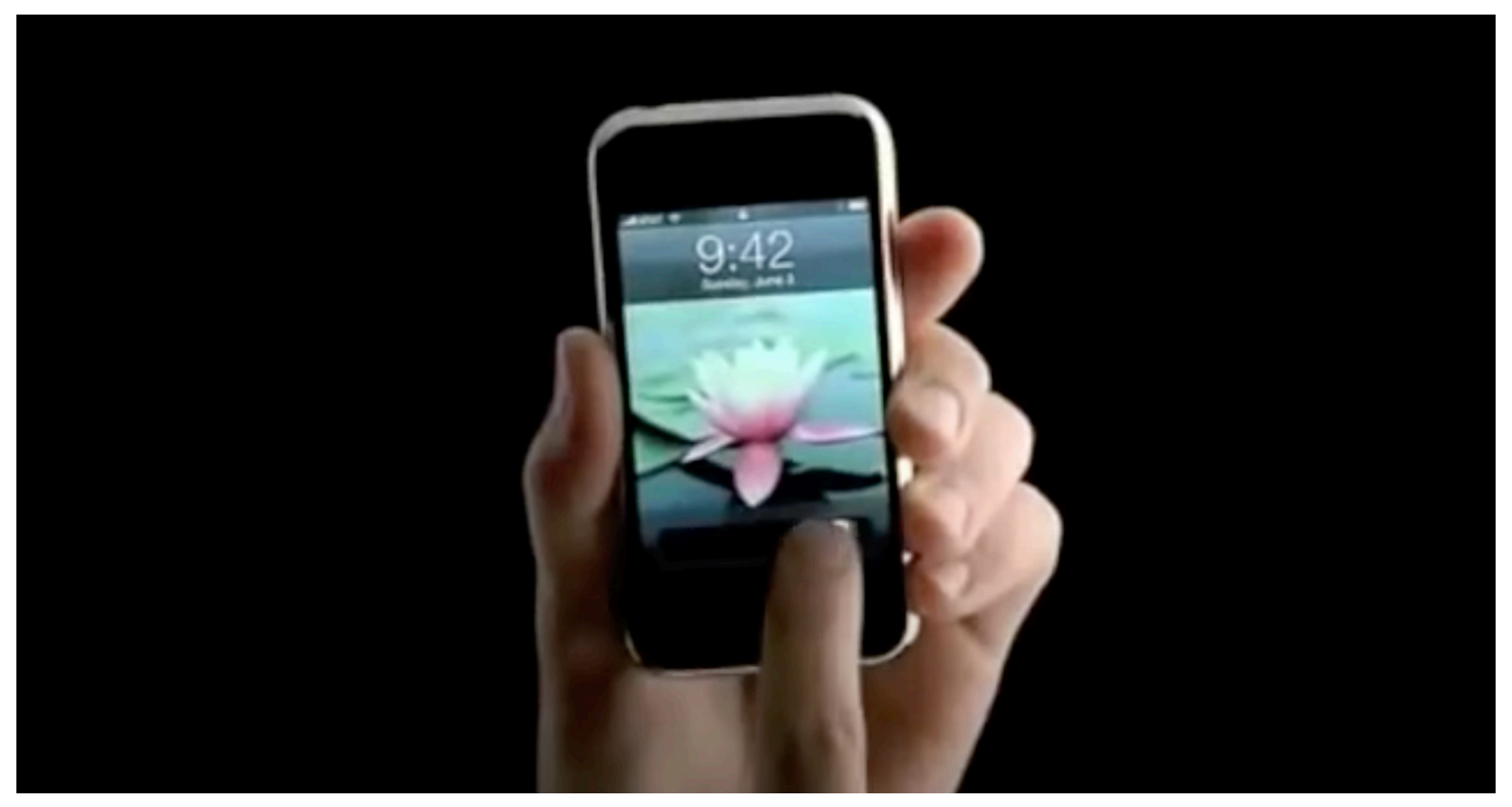

Figure 3

The This is Your iPhone advertisement released in 2007 is 30 seconds, showing consumers how simple its new iPhone is to use. This advertisement was released to highlight the new product, and stir up excitement for the product prior to the release date. By simply showing how different features preform on the device, this advertisement is somewhat of a "show and tell" for the audience about how this new product preforms. This minimalistic and high contrast advertisement seen in figure 3 appeared personal and intimate, drawing in the consumer and making the new technology, with a new and seemingly radical single screen design with no keyboard accessible and friendly. 
The advertisement simply shows a hand holding an iPhone and navigating through various tasks that the new iPhone allows users to complete like checking email, surfing the web, and getting a call. Although it is never mentioned, this advertisement subtly acknowledges the criticisms from the public about the single screen design. Other popular phones on the market at the time were keyboard-centric, making this design radical and unique in the cellphone market (West \& Mace, 2010).

This minimalistic advertisement uses colour only to show the experience on the iPhone featuring very little colour. The solid black background is interrupted by a white males hand holding a black iPhone. The only colour in the advertisement comes from the iPhone itself. The saturation of this ad is relatively high. The black background provides a stark contrast for the colours coming from the screen of the iPhone and the colours used on the iOS. This advertisement draws on the stark contrast between the value of the colours. The black background has a very low value whereas the hand from the white male has a high value, and contrasts from the low value of the dark backdrop. This contrast is repeated as the male hand is holding a black iPhone. Lastly, the black iPhone is showing a user completing different tasks with the bright screen yet again contrasting from the black iPhone itself. The minimal nature of this advertisement uses light to highlight the hand holding the phone itself, and the design of the device itself against the black background drawing again on a high contrast model to draw attention to the product being advertised.

The spatial organization also draws on the personal nature of the advertisement itself. The perspective of this advertisement shows the hand and iPhone straight on in the middle of the 
frame. This advertisement is shot as a close up on the hand holding the iPhone. This shot distance is maintained other than when the user is opening a new application on the home screen of the phone itself, then the camera zooms in on the respective button.

How the advertisement is edited together furthers the personal nature yet again. This advertisement is cut together to appear as if it is one synchronous shot. When the user toggles through applications on the iPhone home screen the camera zooms in on the finger, showing the viewer which app icon is being clicked on. Other than to highlight the application that is being selected the only other transition is at the end of the advertisement to display the name of the new product "iPhone" the carriers that will carry the phone, and then Apple logo with the "June 29" release date.

For sound the advertisement features an upbeat and playful simple and clean melody with male narration. The narrator casually explains how the users completes tasks on the device with the melody playing softly underneath the narration. By explaining how to turn on the phone, listen to music, use email and web, and take a call, this advertisement dissuades any criticism that may stem from the new minimal seamless design.

The overall mood of this advertisement is upbeat, and shows how easy this new technology is to navigate. With the iPhone being the first iteration of the technology for Apple, creating an approachable and friendly advertisement that shows how tasks can be completed with ease shows viewers how simple this new technology is to use before they have the chance to see one in person. 


\section{Interpretation of findings}

By using a combination of minimalism, disruption, and experience, Apple is able to situate its products in the saturated personal electronics market as innovative. Apple conveys innovation through its carefully curated brand that revolves around the users emotion more than the products themselves as demonstrated in the 1984, Are You Gonna be My Girl, and This is your iPhone video advertisements. By highlighting the users experience with a product over the technological features themselves, Apple is able to draw on users' desire for an enjoyable experience to sell its products. A comprehensive visual analysis solidifies the ways in which Apple has curated its brand and chosen to frame its products to the masses through advertising. By using movement, Apple is able to demonstrate the experience of using its products in contrast to the still nature of print advertising, while maintaining a brand identity consistent across advertising mediums.

Apple has carefully crafted a unified and cohesive brand known for its trademark minimal aesthetic and sleek product design. By using a minimal aesthetic in both its products physical design and advertising, Apple's cohesive brand identity has created a very clear and detectable style within the personal technology market. By creating products with a sleek and simple minimal design, Apple is able to draw on the idea that the design of an item communicates information to customers, using its unique sleek design to its advantage (Blosh, 1995). This sleek and simple product design communicates to the consumer that the user interface will mirror the simple and sleek external product design, as consumers attribute qualities of the physical device to the experience of using it (Liu et al., 2017). This idea is alluded to and demonstrated in the This is Your iPhone advertisement which highlights how 
simple it is to complete tasks people are used to doing on their phones like surfing the web and checking emails on the device. Although there are only five tasks that are demonstrated in the short advertisement, Apple is relying on the idea that viewers will use their imaginations, and previous knowledge and experiences to attach further meaning to the item, even before using it themselves (Durgee et al., 2016).

A unified brand identity has allowed Apple the freedom to highlight the experience of the product more than the product itself. After 1984, and the initial introduction to the brand, Apple was able to draw on consumers' image of its products as innovative, and on how the products make potential users feel. This focus on the experience of the product adds to the hype and social value of the product, placing the item, and the entire Apple brand in the psyche of the public as a marker of status and value (Hedman \& Gimpel, 2010). With the knowledge that product design has a strong relation to a product's market success, Apple is able to draw on sharing minimal information about the product itself but rather rely on the design to act as a product feature, insinuating that the rest of the device is as innovative as the design may be compared to other items on the market (Liu et al., 2017; Talke et al., 2009).

It is within this idea of perceived innovation that has lead to Apple products being considered somewhat of a status symbol. This idea of status undeniably helps Apple as a brand to sell products to consumers. This is in part because its radical minimal design conveys innovation and better performance to the public (Xue et al., 2019). The Apple brand identity has become synonymous with a consumer identity of innovation and modernity, and has come to demonstrate that owners of the products stay in touch with trends (Talke et al., 2009). By curating a brand 
identity that revolves around contrasting itself from the other items available to consumers, and the experience of using its products, Apple has been able to situate its products as a marker of status and innovation.

A contributing factor to the status and innovation associated with Apple products is its use of contrast. By using contrast, Apple is able to highlight its products in a clean and simple environment, in opposition of the other similar items on the market. Demonstrated in the 1984, Are You Gonna be My Girl and This is Your iPhone advertisements, contrast is used to highlight the Apple product and reinforce brand identity. In the 1984 advertisement, contrast is used to create a demonstration of the 'dark ages' before the hammer is thrown at the screen, and the bright future once the Macintosh computer is introduced. This advertisement was the first of its kind for Apple and was played during the Super Bowl, giving the brand a very public introduction to the public. Another interesting note about the 1984 ad is that the new Macintosh computer itself is never actually shown at all. Rather, the contrast of life before and after the product is highlighted. Depicting a world full of 'mindless' and 'dull' followers, Apple frames itself as new, innovative, and unique, or at the base level, disruptive to the current market. By not focusing on the product itself, the 1984 advertisement simply situates the brand as a company which is not complacent in what is currently happening, and is not scared to disrupt the market.

By consistently framing itself using contrast, Apple is able to situate its brand in the minds of consumers as different than the competing products on the market. The use of contrast not only highlights the brand identity, but it also frames the Apple brand as offering a new and innovative version of an existing technology. Furthermore, by consistently using contrast as a 
facet of the brand identity, Apple is able to draw on pre-existing positive public opinion to sell products and focus more on simply reinforcing that its products are different without having to necessarily highlight how. In these stark, simple environments used in its advertisements, Apple uses its products to provide symbolic information to consumers like product innovation and increased performance quality (Xue, 2019). By creating an advertisement witch highlights the product experience, and shows consumers the sleek minimal design of the products, Apple is able to then persuade viewers that its products are innovative, by simply not referencing any of the technical components of the item being sold. Understanding the power of product design on consumer opinion, Apple is able to rely on its unique brand identity and product design to harness a competitive advantage over other companies with more popular and mainstream designs (Gilal et al., 2018).

Similarly to contrast, Apple has used disruption to situate itself in the psyche of the public. As first shown in the 1984 commercial, the entire brand identity was introduced by highlighting the disruption of the status quo brought on by the introduction of Apple products. Although selling products with radical designs has seemingly worked for Apple, there is generally an underlying reluctance from consumers to adapt new products, whereas the market generally follows consumer tastes, Apple has built its reputation around leading consumers (Durgee et al., 2016). These advertisements highlight the ways in which Apple products differ from other seemingly boring computing products through radical design, resituating personal technology as an opportunity for an enjoyable experience. Through a mixture of radical and minimal design, and a cohesive brand identity built on contrasting from other similar products on the market, Apple situated itself as a brand that improves upon technologies and makes them 
exciting and cool. As Apple became increasingly known for a unique product design, it is able to garner a significant amount of attention because of its disruption to the status quo. Research by Liu et al. (2020) concluded that the more unique a product design, the more attention it will receive from the public purely based off of aesthetics. The Macintosh computer, iPod, and iPhone were not the first products to serve their specific function however their unique design and the Apple corporate character was able to disrupt the markets of the existing products (West \& Mace, 2010). The power of the Apples brand was so strong that in 2007 when the iPhone was released in the United States it quickly became the most successful new entrant to the mobile phone marketplace (West \& Mace, 2010).

Although known for a minimal brand aesthetic, Apple uses colour in advertisements to highlight an emotion or feeling. In the Are You Gonna be My Girl advertisement colour is used to highlight the fun playful nature of the brand. The bright and playful colours as the solid background providing contrast to the silhouettes further demonstrated the happy and joyful experience of using an iPod. Colour is also used in the 1984 advertisement contrasting the bluish grey dark room with the woman's red shorts. These red shorts also contrast the long grey jumpsuits of the followers. By using colour intentionally to highlight an item or mood, Apple has carefully curated a minimalistic brand that uses colour to highlight an emotion or feeling rather than just to make the material or items more friendly or approachable (Talke et al., 2009).

Additionally, Apple uses experience to sell its products through advertising. The focus on experience over the product itself can be seen in the Are You Gonna be My Girl commercial. By highlighting how much fun the silhouettes are having dancing and listening to music from their 
iPods Apple is able to highlight experience over the product itself. This strategy is useful when drawing up excitement from the public because Apple is able to insinuate that this new product offers a level of excitement, innovation and freedom that has not been offered by other products. The This is Your iPhone advertisement also draws on this concept whereas when the phone itself is being presented Apple focuses on the experience of completing popular tasks done on a mobile phone like looking at emails, surfing the web, and taking a phone call. By highlighting the experience of using the product Apple is able to generate excitement for the product through appealing to consumers' emotions rather than relying on explaining the technology behind the device itself. This idea of experience is even alluded to in the 1984 commercial, although less overtly. By showing a dull world full of 'followers' Apple situates itself as a new and unique alternative to the status-quo.

Although the This is Your iPhone advertisement uses experience to promote its product it strays from the aforementioned model whereas the experience of owning the product is shown more than the product itself. To understand this advertisement, it is important to understand the social context of the time. In 2007, Canadian technology giant Blackberry was leading the smartphone market with, email-centric business oriented phones (West \& Mace, 2010). 


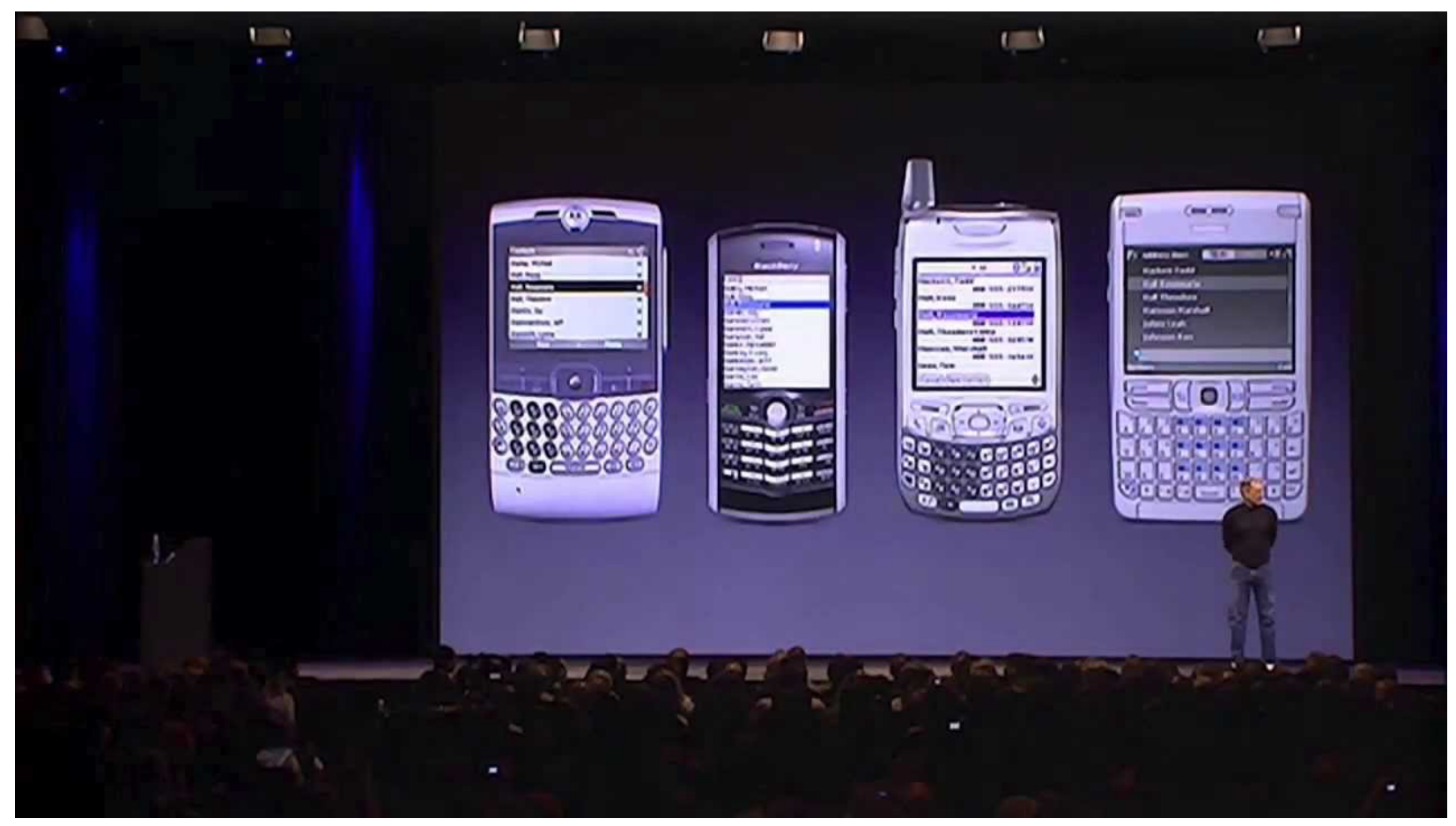

Figure 4

Blackberry phones were known for their trademark keyboard and small screen design, seen in Figure 4, that had taken over the market (West \& Mace, 2010). The Blackberry design had become standard within the cellphone industry, and immediately placed the iPhone in the minds of consumers as innovative upon its release as a result of its large screen and the removal of the keyboard hardware. With this context in mind, the physical design of the iPhone was disruptive to what consumers were accustomed to. The new iPhone did not have a permanent keyboard, rather these phones just boasted one large screen that can become a keyboard when necessary, but also allows for ease of browsing the web, and the brand consistent Apple sleek and minimal product design.

The This is your iPhone advertisement then, while following the Apple brand of using contrast to highlight the product by having the hand of a man with light skin hold the black 
phone over a solid background, was able to confront thoughts consumers may have about the phone being difficult to use because of the new keyboard less design. By simply showing how common tasks are completed on the device without acknowledging the concerns directly Apple is able to control its image and maintain its innovative, disruptive and minimal aesthetic. This is an example of Apple using the design of its products to emphasize the innovation of its product on the market, without having to explicitly say it.

This strategy is in part what has lead Apple to be seen as a cool brand. Without boring consumers with the details of how the technology works, Apple has given consumers a chance to just focus on the product, and how it makes them feel; leaving the technical stuff to Apple. This model exemplifies the minimal and cool aesthetic of the Apple brand and amplifies the cool laid back brand identity.

The Apple brand becoming a status symbol itself undeniably helped the company sell products to consumers. Apple products became a marker of social value to others, making the owner look cool because they own the expensive technology that would likely become a centrepiece of conversation (Hedman \& Gimpel, 2010). The radical design of its products quickly became a marker of the Apple brand, with the first Macintosh computer being seen as personifying friendliness, alongside innovation and status (Blosh, 1995). By designing products that consumers are already familiar with like computers, music players, and cell phones, Apple has been able to embed its new designs in existing technologies, easing the integration into consumers lives (Cecilia Russo \& Ferrara, 2017). However, differing in design from other items on the market, Apple was able to take advantage of the fact that consumers generally view 
products that look cool as being more valuable, and are more likely to purchase these items (Xue, 2019).

By maintaining the trademark minimal brand aesthetic, Apple has been able to leverage its advertising to be uniquely its own, not having to worry about its marketing subsequently promoting a competing products (Liu et al., 2017). The unique brand identity has also helped Apple reinforce its brand identity by using very little copy, as the designs and aesthetics, which are unique to Apple, are able to speak for themselves, again reinforcing the minimal aesthetic seen in the Are You Gonna Be My Girl and This is Your iPhone advertisements (Durgee et al., 2016). It is within this model of unique brand identity and minimalism that Apple has been able to control the discourse of its products, blurring the lines between speculation of what the product might be able to do and the reality of the technical components of the device (Hedman \& Gimpel, 2010).

\section{Conclusion}

This research paper looks at the ways that Apple uses video advertising to convey innovation in its products, and - in doing so - how its products have become cool status symbols. The marketing and communications literature suggests how Apple and other companies use branding and design to convey innovation. Based on this body of existing knowledge, this paper used a visual analysis of three Apple commercials to explore the company's use of these branding techniques and interprets the findings. 


\section{Significance of Findings}

Successful branding is important for a company, especially in a postmodern world. It becomes a sort of shorthand, communicating an implied promise of numerous attributes and triggering strong emotional responses. Using a combination of unique product design and branding, Apple has been able to position itself as an innovative brand. Analysis of a few of its most iconic commercials - specifically 1984, Are You Gonna be My Girl, and This is Your iPhone - suggest that Apple has been successful by focusing on a few key elements in its video advertising; contrast, disruption, and experience.

Its continuous use of contrast reinforces Apple as being different from its competitors. For example, its use of colour creates a sharp contrast for its portrayal of the world before and after the Macintosh computer in its 1984 commercial.

Apple's brand conveys disruption, and it reinforces that message in its video advertising. It alludes to disruption in Are You Gonna be My Girl, and This is Your iPhone, and does so overtly in 1984 , thus using video advertising to position its products as disruptive to the other items on the market in the same product categories. Disruption generally compares new products to consumers' other options, and Apple's video advertisements convey liberation for those who own the products.

The company also communicates this sense of liberation in the experiential element of its video advertisements. By communicating the affective or emotional dimension of owning and using Apple products, it helps consumers to imagine the feeling of owning an Apple product rather than focusing on the unemotional technical features of the products themselves. 
Highlighting the experience of using the item rather than the technical specifications has helped Apple position itself as an innovative and cool brand (Firmin et al., 2013).

Overall, its unique, minimalist style supports its brand identity and Apple has built that cohesive brand to frame its entire product line as clever, innovative status symbols that increase their owners' social status. It does this by focusing on the experience of using the product, highlighting the ease and joy of use, rather than explaining the technology itself. The real value of the brand, of promising a great user experience and innovative design, is that it positions the user themselves as cool for having chosen products that offer a great experience and clever design. Being a status symbol with a loyal market allows Apple to continue to succeed within the technology market. Whereas most competition highlights the technological features of the products, Apple simply highlights the experience of using its goods within a clean and contrasting framework.

Apple's unique and radical product design undeniably has had a positive impact on consumer perception of the brand. The trademark minimal style and consistent brand identity in video advertisements has been able to insinuate that Apple products are technologically innovative. This focus on the unique design and experience of the device is able to focus consumers on how the device feels, differentiating itself from the other comparable products on the market. By using differentiation, the power of Apple products becomes more about how it is different than other items available, and less importantly about how the technological features of the item itself. This idea of contrasting Apple products from other similar options on the market has allowed Apple to focus more on highlighting how it is different, and how these differences 
improve the user experience opposed to highlighting the products' specific technological features.

\section{Limitations and Implications}

The scope of this research paper limited the number of advertisements for which I was able to do an extensive visual analysis. To do a comprehensive analysis within that scope, I completed a visual analysis on three Apple video advertisements. These three commercials 1984, Are You Gonna be My Girl, and This is Your iPhone - represent a sampling of different periods and products for Apple. Although themes from this research extend beyond the three artifacts that I analyzed, and can be seen in other Apple advertisements, this research is not a comprehensive analysis of all advertising material. Further, the three advertisements examined in this research are from between the period of 1984-2007; a time period that represents Apple's launch and early advertisements, but does not take into consideration its newer advertising practices.

Another limitation of this research is the fact that 1984 was a one-minute Super Bowl advertisement and follows a different format than the other two 30 second advertisements. This advertisement was chosen because it was Apple's first video advertisement, and set the tone for themes seen in its advertising going forward. This Super Bowl advertisement, and the other advertisements studied only consider the North American market and reception. Although Apple has disseminated video advertising worldwide, for the sake of this research, only the North American market is studied. 
That said, this research helps explain how Apple has been able to frame itself in the public psyche as an innovative brand through video advertising.

\section{Concluding Remarks}

Apple has been able to successfully position its products as innovative and cool in the personal electronics marketplace. Beginning with the success of the Macintosh personal computer, Apple situated itself in the psyches of the public as a cool and technologically innovative brand (Firmin et al., 2013). Its popularity and status has led consumers and industry watchers alike to expect Apple to consistently offer products with great user experience and radical designs to the public. This has other implications for Apple. While companies traditionally seek to follow consumer trends, Apple has become known for driving the trends itself, through its trademark minimalistic and radical product design (Durgee et al., 2016).

The visual analysis is this study suggests that Apple uses experience, disruption, and contrast to position its products. The Apple brand thus insinuates that its products offer liberation from the status quo, helping to position its products as cool, and, by extension, their users (Hedman \& Gimpel, 2010). To further support its brand, Apple sells its products in iStores, a fully-curated channel that differs from the other options on the market.

The body of marketing research looks at the myriad ways in which consumers are swayed by product design and product newness, but few explore how Apple uses its branding and aesthetic to persuade consumers that its products are superior to competitors. Studies within branding and product innovation address how consumers perceive products on the market with 
radical product designs, and the benefits of having a cohesive brand identity (Veryzer \& Hutchinson, 1988). Delving into previous literature regarding the impacts of product design, branding, and conveying innovation, this research goes beyond these themes to explore how Apple can harness its brand to convey to consumers that its products are cool and innovative.

Apple has been able to frame itself as cool and innovative. In doing so, it has cultivated a favourable image in the public psyche and built a loyal following. Focusing on its brand image, and not on the technical aspects of its products, including radical design and user experience, Apple has been able to convey innovation and cool (Talke et al., 2009). Organisations that seek to build long-term success in crowded marketplaces can learn from these examples. However, like Apple, they will need to commit to long-term support for the brand at every point of contact, and to reinforcing its customers' sense of pride for having made the choice. 


\section{References}

Apple. (2003). Are You Gonna Be My Girl [Television commercial]. Retrieved from https:// www.youtube.com/watch?v=TaVFCdwT0hk

Apple. (2007). This is Your iPhone [Television commercial]. Retrieved from https:// www.youtube.com/watch? $\mathrm{v}=\mathrm{oJ} 4 \mathrm{k} 1 \mathrm{QIXoSU}$

Apple. (1984). 1984 [Television commercial]. Retrieved from https://www.youtube.com/watch? $\mathrm{v}=\mathrm{VtvjbmoDx}-\mathrm{I}$

Bloch, P. H. (1995). Seeking the ideal form: Product design and consumer response. Journal of Marketing, 59(3), 16-29. https://doi.org/10.1177/002224299505900302

Cecilia Russo, A., \& Ferrara, M. (2017). Smart solutions, "smart aesthetics"? The Design Journal, 20, S342-S353. https://doi.org/10.1080/14606925.2017.1352872

Dong, A. (2015). Design $\times$ innovation: Perspective or evidence-based practices. International Journal of Design Creativity and Innovation, 3(3-4), 148-163. https://doi.org/10.1080/21650349.2014.943294

Durgee, J., Markovitch, D., \& Huang, D. (2016). How to advertise radical product designs. The Design Journal, 19(4), 647-666. https://doi.org/10.1080/14606925.2016.1176348

Eggink, W., \& Snippert, J. (2017). Future aesthetics of technology; context specific theories from design and philosophy of technology. The Design Journal, 20(Suppl. 1), S196S208. https://doi.org/10.1080/14606925.2017.1352748

Gehani, R. R. (2016). Corporate brand value shifting from identity to innovation capability: From coca-cola to apple. Journal of Technology Management \& Innovation, 11(3), 11-20. https://doi.org/10.4067/S0718-27242016000300002

Gilal, N. G., Zhang, J., \& Gilal, F. G. (2018). Linking product design to consumer behavior: The moderating role of consumption experience. Psychology Research and Behavior Management, 11, 169-185. doi:10.2147/PRBM.S161384

Graham, M. (2019) Apple's ad agency has layoffs as the company beefs up its in-house ads group. $C N B C$. https://www.cnbc.com/2019/11/05/apples-advertising-agency-media-artslab-lays-off-several-employees.html

Holtzhausen, D. (2000). Postmodern values in public relations. Journal of Public Relations Research, 12(1), 93-114. doi:10.1207/S1532754XJPRR1201_6 
Jobs, S. (2007, January 9). iPhone Keynote [Address]. Macworld Conference, San Francisco, U.S. https://www.youtube.com/watch?v=VQKMoT-6XSg

Keller, K. L. (2013). Strategic brand management: Building, measuring, and managing brand equity. Global Edition. (4th ed.) Pearson.

Liu, F., Zhu, Z., Chen, H. \& Li, X. (2020). Beauty in the eyes of its beholders: Effects of design novelty on consumer preference. Journal of Retailing and Consumer Services, 53, 101969. https://doi.org/10.1016/j.jretconser.2019.101969

Liu, Y., Li, K. J., Chen, H. \& Balachander, S. (2017). The effects of products' aesthetic design on demand and marketing-mix effectiveness: The role of segment prototypicality and brand consistency. Journal of Marketing, 81(1), 83-102. https://doi.org/10.1509/jm.15.0315

Pountain, D., \& Robins, D. (2000). Cool Rules: Anatomy of an Attitude. London: Reaktion.

Spaulding, T. J. (2010). How can virtual communities create value for business? Electronic Commerce Research and Applications, 9(1), 38-49. doi:10.1016/j.elerap.2009.07.004

Talke, K., Salomo, S., Wieringa, J.E. and Lutz, A. (2009). What about Design Newness? Investigating the Relevance of a Neglected Dimension of Product Innovativeness. Journal of Product Innovation Management, 26: 601-615. https://doi.org/10.1111/j.1540-5885.2009.00686

Veryzer, R., and Hutchinson, W. (1998), "The Influence of Unity and Prototypicality on Aesthetic Responses to New Product Designs," Journal of Consumer Research, 24 (4), 374-85.

West, J., \& Mace, M. (2010). Browsing as the Killer App: Explaining the Rapid Success of Apple's iPhone Elsevier Ltd. doi:10.1016/j.telpol.2009.12.002

Wilner, S. J. S., \& Huff, A. D. (2017). Objects of desire: The role of product design in revising contested cultural meanings. Journal of Marketing Management: Design, Consumption, and Marketing, 33(3-4), 244-271. doi:10.1080/0267257X.2016.1240099

Xue, J. (2019). An investigation into the effects of product design on incremental and radical innovations from the perspective of consumer perceptions: Evidence from china.

Creativity and Innovation Management, 28(4), 501-518.

https://doi.org/10.1111/caim.12329 


\section{Back Matter}

\section{Appendix A: Visual analysis of Figure 1}

\begin{tabular}{|c|c|c|}
\hline \multicolumn{2}{|c|}{ Compositional Frame } & Observation \\
\hline \multicolumn{2}{|l|}{ Content } & $\begin{array}{l}\text { This advertisement features an ominous cult-like } \\
\text { world where a crowd of gender neutral people all } \\
\text { gather to listen to the leader before a woman runs } \\
\text { in, evading security with a hammer and throws it } \\
\text { at the screen. Once the hammer pierces the screen } \\
\text { all the people in the room appear stunned and } \\
\text { frozen in shock. }\end{array}$ \\
\hline \multirow[t]{3}{*}{ Colour } & Hue & $\begin{array}{l}\text { The advertisement is mostly grey, with the world } \\
\text { and the wardrobes of those in it all cool toned } \\
\text { shades. This is contrasted by the woman who runs } \\
\text { in wearing red shorts and white tank top. }\end{array}$ \\
\hline & Saturation & $\begin{array}{l}\text { At the beginning of the ad the scenes have a very } \\
\text { low saturation, with the world featuring many } \\
\text { muted blue-grey tones. It is not until the antagonist } \\
\text { female is shown on screen in bright red shorts and } \\
\text { a stark white tank top that there is highly saturated } \\
\text { colour. After the hammer is thrown the world } \\
\text { shown on screen becomes lighter as those } \\
\text { followers become still and there saturation of the } \\
\text { whole scene becomes more saturated. }\end{array}$ \\
\hline & Value & $\begin{array}{l}\text { Colour value in this ad provides additional context } \\
\text { and contrast to the advertisement. Whereas the } \\
\text { value of the beginning of the advertisement has a } \\
\text { very low value, with the entire scene in hues of } \\
\text { dark blue and grey, ends with a bright white scene } \\
\text { after the hammer is thrown at the screen. The } \\
\text { colour value of the antagonist is also contrasting } \\
\text { from those 'followers' seen filing into the theatre. } \\
\text { Whereas the 'followers' are wearing a grey } \\
\text { jumpsuit, the antagonist is wearing a high value } \\
\text { white tank top and bright red shorts. }\end{array}$ \\
\hline
\end{tabular}




\begin{tabular}{|c|c|c|}
\hline \multirow[t]{2}{*}{ Spatial Organisation } & $\begin{array}{l}\text { Geometrical } \\
\text { Perspective }\end{array}$ & $\begin{array}{l}\text { The perspective of this advertisement shifts as it } \\
\text { progresses. The 'followers' are always shown from } \\
\text { the ground looking up or above looking down. } \\
\text { This is contrasted by the antagonist who is shown } \\
\text { straight on at eye level until she is throwing the } \\
\text { hammer and the camera is looking up at her as } \\
\text { well. }\end{array}$ \\
\hline & Shot Distance & $\begin{array}{l}\text { This advertisement features a use a combination of } \\
\text { long, medium, and close-up shots. }\end{array}$ \\
\hline Montage & & $\begin{array}{l}\text { The scenes in this advertisement jump around } \\
\text { quite quickly creating a jarring and high tension } \\
\text { montage rhythm for the viewer. These clips begin } \\
\text { wide and get closer and closer to the 'followers' as } \\
\text { the camera follows them heading to a theatre to } \\
\text { listen to a message on a large screen. }\end{array}$ \\
\hline Sound & & $\begin{array}{l}\text { Sound is used to further the narrative for this } \\
\text { advertisement. As the ad begins there is the sound } \\
\text { of a mans voice muffled coming from what sounds } \\
\text { like a loudspeaker, however you are not able to } \\
\text { hear where it is coming from until the 'followers' } \\
\text { enter the theatre and you can see a man on the } \\
\text { screen speaking to the people watching. This man } \\
\text { is interrupted by the antagonist woman yelling as } \\
\text { she throws the hammer followed by a cleaner } \\
\text { voice reading the text that appears on screen "On } \\
\text { January } 24 \text { th, Apple Computer will introduce } \\
\text { Mackintosh. And you'll see why } 1984 \text { won't be } \\
\text { like "1984." }\end{array}$ \\
\hline Light & & $\begin{array}{l}\text { This advertisement uses light to highlight the } \\
\text { progression of the storyline. By introducing a dark } \\
\text { scene, when the antagonist is shown in lighter } \\
\text { clothes she immediately stands out from the others } \\
\text { shown in the scene. Once the hammer is thrown } \\
\text { into the screen and the text begins to play overlaid } \\
\text { on the scene light is used to provide contrast for } \\
\text { what Apple is insinuating as the dark world before } \\
\text { the Mackintosh computer, and the brighter future. }\end{array}$ \\
\hline
\end{tabular}



optimism. Clearly depicting 'followers' blindly following each other around, this advertisement situates Apple as disruptive to the current statusquo.

\section{Appendix B: Visual analysis of Figure 2}

\begin{tabular}{|l|l|l|}
\hline \multicolumn{2}{|c|}{ Compositional Frame } & \multicolumn{1}{c|}{ Observation } \\
\hline Content & $\begin{array}{l}\text { This is an upbeat advertisement depicting people } \\
\text { dancing energetically to music presumably from } \\
\text { their iPods with headphones in. These minimalist } \\
\text { ad's display nothing but the silhouette of the } \\
\text { subjects in black atop a colourful background } \\
\text { holding an iPod and wearing Apple's trademark } \\
\text { white corded headphones. }\end{array}$ \\
\hline Colour & Hue & $\begin{array}{l}\text { This advertisement features a very minimalistic } \\
\text { and streamline colour palate. The only colour used } \\
\text { in the ad is the background of the ad itself, which } \\
\text { alternates between lime green, yellow, hot pink } \\
\text { and purple. The only other items in the ad are the } \\
\text { black silhouette of the dancer and the white iPod } \\
\text { they are holding in their hand. }\end{array}$ \\
\cline { 2 - 3 } & Saturation & $\begin{array}{l}\text { The background colours used are highly saturated. } \\
\text { Atop these highly saturated colourful backdrops } \\
\text { the other items in the ad provide a stark contrast, } \\
\text { as the black dancing figure is holding the white } \\
\text { iPod and wearing white headphones so the product } \\
\text { being advertised stands out even more. }\end{array}$ \\
\hline Value & $\begin{array}{l}\text { This advertisement plays on a stark contrast in the } \\
\text { value of the colours used. As black has a very low } \\
\text { value, the colourful backdrops and white iPhone } \\
\text { have very high values. The contrasting values used } \\
\text { in this ad make it very simple, but also highlight } \\
\text { because of contrast that the iPod as an important } \\
\text { feature of the advertisement. }\end{array}$ \\
\hline &
\end{tabular}




\begin{tabular}{|l|l|l|}
\hline Spatial Organisation & $\begin{array}{l}\text { Geometrical } \\
\text { Perspective }\end{array}$ & $\begin{array}{l}\text { The dancers in the advertisement are shown at eye } \\
\text { level and through close ups of the dancers to show } \\
\text { the movement of the clothing, and highlight the } \\
\text { fact that the dancers are singing along to the song } \\
\text { being played in the advertsment. }\end{array}$ \\
\cline { 2 - 3 } & Shot Distance & $\begin{array}{l}\text { This advertisement features a use a combination of } \\
\text { long, medium, and close-up shots. }\end{array}$ \\
\hline Montage & $\begin{array}{l}\text { The clips in this advertisement are put together to } \\
\text { switch almost seamlessly to the beat of the song } \\
\text { playing in the ad. These clips are a combination of } \\
\text { different shot distances combined in a way which } \\
\text { highlights the silhouettes dancing and singing } \\
\text { along to the song playing. The camera does not } \\
\text { move during any of the clips. }\end{array}$ \\
\hline Sound & $\begin{array}{l}\text { Are You Gonna Be My Girl by rock group Jet is } \\
\text { the only sound in the advertisement. Beginning } \\
\text { with a heavy guitar solo, then the lyrics "So one, } \\
\text { two, three, take my hand and come with me; } \\
\text { Because you look so fine; That I really wanna } \\
\text { make you mine; I say you look so fine; That I } \\
\text { really wanna make you mine; Oh, four, five, six } \\
\text { c'mon and get your kicks; Now you don't need the } \\
\text { money; When you look like that, do ya honey?" } \\
\text { bringing the viewer to the end of the } \\
\text { advertisement. }\end{array}$ \\
\hline Light & $\begin{array}{l}\text { Not applicable. } \\
\text { Expressive Content } \\
\text { The "mood" of this advertisement is happy and } \\
\text { upbeat. The combination of the upbeat rock song, } \\
\text { bright colours, and dancing and singing along that } \\
\text { the silhouettes are doing make the ad fun to watch. }\end{array}$ \\
\hline
\end{tabular}

\section{Appendix C: Visual analysis of Figure 3}




\begin{tabular}{|l|l|l|}
\hline \multicolumn{1}{|l|}{ Content } & $\begin{array}{l}\text { This advertisement shows a hand holding an } \\
\text { iPhone and navigating through various tasks that } \\
\text { the new iPhone allows users to complete. }\end{array}$ \\
\hline Colour & Hue & $\begin{array}{l}\text { This minimal advertisement features very little } \\
\text { colour. The black black background is interrupted } \\
\text { by a white male's hand holding a black iPhone. } \\
\text { The only colour in the advertisement comes from } \\
\text { the iPhone itself. }\end{array}$ \\
\cline { 2 - 3 } & Saturation & $\begin{array}{l}\text { The saturation of this ad is relatively high. The } \\
\text { black background provides a stark contrast for the } \\
\text { colours coming from the screen of the iPhone and } \\
\text { the colours used on the iOS. }\end{array}$ \\
\cline { 2 - 4 } & $\begin{array}{l}\text { Value } \\
\text { This advertisement draws on the stark contrast } \\
\text { between the value of the colours. The black } \\
\text { background has a very low value whereas the hand } \\
\text { from the white male has a high value, and } \\
\text { contrasts from the low value of the dark backdrop. } \\
\text { This contrast is repeated as the male hand is } \\
\text { holding a black iPhone. Lastly, the black iPhone is } \\
\text { showing a user completing different tasks with the } \\
\text { bright screen yet again contrasting from the black } \\
\text { iPhone itself. }\end{array}$ \\
\hline Spatial Organisation & Shot Distance \\
Perspective & $\begin{array}{l}\text { The perspective of this advertisement shows the } \\
\text { hand and iPhone straight on in the middle of the } \\
\text { frame. }\end{array}$ \\
\hline $\begin{array}{l}\text { This advertisement is shot as a close up on the } \\
\text { hand holding the iPhone. This shot distance is } \\
\text { maintained other than when the user is opening a } \\
\text { new application on the home screen of the phone } \\
\text { itself, then the camera zooms in on the respective } \\
\text { button. }\end{array}$ \\
\hline
\end{tabular}




\begin{tabular}{|l|l|}
\hline Montage & $\begin{array}{l}\text { This advertisement is cut together to appear as if it } \\
\text { is one synchronous shot. When the user toggles } \\
\text { through applications on the iPhone home screen } \\
\text { the camera zooms in on the finger, showing the } \\
\text { viewer which app icon is being clicked on. Other } \\
\text { than to highlight the application that is being } \\
\text { selected the only other transition is at the end of } \\
\text { the advertisement to display the name of the new } \\
\text { product "iPhone" the carries that will cary the } \\
\text { phone, and then Apple logo with the "June 29" } \\
\text { release date. }\end{array}$ \\
\hline Sound & $\begin{array}{l}\text { The advertisement features a upbeat and playful } \\
\text { simple and clean melody with a male narration. } \\
\text { The narrator says: "This is how you turn it on; } \\
\text { This is your music; This is your email; This is the } \\
\text { web; And this is a call on your iPhone." }\end{array}$ \\
\hline Light & $\begin{array}{l}\text { The minimal nature of this advertisement uses } \\
\text { light to highlight the hand holding the phone itself, } \\
\text { and the design of the device itself against the black } \\
\text { background. }\end{array}$ \\
\hline & $\begin{array}{l}\text { The overall mood of this advertisement is upbeat, } \\
\text { and shows how easy this new technology is to } \\
\text { navigate. }\end{array}$ \\
\hline
\end{tabular}

